UDC 541.64

DOI: $10.33184 /$ bulletin-bsu-2021.4.21

\title{
THE MANIFESTATION OF TEMPORARY VISCOSITY ANOMALIES IN CARBOXYMETHYL CELLULOSE SODIUM SALT SOLUTIONS
}

\author{
(C) R. Yu. Lazdin ${ }^{1}$, M. S. Kotyashov' ${ }^{2}$ M. Yu. Lazdina ${ }^{1}$, \\ V. V. Chernova ${ }^{1}$, E. I. Kulish ${ }^{1 *}$ \\ ${ }^{1}$ Bashkort State University \\ 32 Zaki Validi Street, 450076 Ufa, Republic of Bashkortostan, Russia. \\ ${ }^{2}$ Ufa State Petroleum Technological University \\ 14 Pervomayskaya Street, 450000 Ufa, Republic of Bashkortostan, Russia. \\ *Email: onlyalena@mail.ru
}

\begin{abstract}
The rheological properties of the carboxymethylcellulose sodium salt solutions were studied. It was shown that in a certain concentration regime they exhibit thixotropic properties, i.e. are capable of a reversible decrease in viscosity. It was found that the presence of thixotropic structures in the area of intermediate concentrations, where supramolecular structures are uniquely formed, and the time required for their destruction is comparable with the time of the experiment, makes it possible to regulate some of the physicomechanical properties of materials formed from solutions by varying the level of polymer structure formation in the initial solution.
\end{abstract}

Keywords: rheological properties, polymer solution, viscosity, carboxymethylcellulose, thixotropic properties.

\section{Introduction}

The rheological properties of solutions and polymer melts are known to have a number of features [1-9]. For example, unlike Newtonian fluids, the viscosity of which is a constant $\eta=$ const, the viscosity of polymeric fluids (so-called pseudoplastic fluids) can behave abnormally, for example, depend on the magnitude of the applied stress or shear rate, most often decrease. Temporal anomalies can also appear: the viscosity of solutions or melts of polymers under the influence of a constantly acting shear rate can change over time, as a rule, decrease. The viscosity-lowering effect can be reversible, in which case the initial high viscosity at rest can be restored. The phenomenon of a reversible change in viscosity is called thixotropy, and liquids exhibiting this effect are called thixotropic. [10-13]. This property appears to be extremely useful in the development of, for example, liquid dosage forms, food, cosmetics and pharmaceuticals. The phenomenon of thixotropy is only inherent for structured systems, for example, coagulation dispersed systems or solutions and melts of polymers with a certain structure, the destruction and recovery of which takes time. A characteristic property of a thixotropic liquid is the ability to restore its structure whenever it remains at rest for a sufficiently long period of time. The manifestation of thixotropic properties by the system is in fact a confirmation of the presence of a supramolecular structure formed through weak bonds. Considering that the structure formation of polymers in solution has a significant effect on the entire range of properties of materials obtained from solutions, such as fibers or films [14-19], the study of the thixotropy effect as a measure for assessing the structure of a solution is of absolute importance. Thus, the aim of this work was to study the thixotropic properties of aqueous solutions of sodium salt of carboxymethylcellulose. The choice of the research object was due to the spectrum of polymer properties [20-21] and its wide application [23-28].

\section{Experimental}

We used sodium salt of carboxymethylcellulose (CMC) with a degree of substitution $\gamma=70 \%$ and with molecular weight $260000 \mathrm{cDa}, \mathrm{pH}=7.2$.

Distilled water served as a solvent for CMC. The concentration of $\mathrm{CMC}$ in the solution varied from 0.1 to $5 \mathrm{~g} / \mathrm{dl}$. Films were obtained by pouring a CMC solution onto the glass surface of a Petri dish. Rheological studies were carried out on a HaakeMarsIII modular dynamic rheometer at $25{ }^{\circ} \mathrm{C}$ in the shear deformation mode. The study of mechanical properties was carried out on an AGS-10 kNG "Trapezium-X" tensile testing machine of the "Shimadzu" brand equipped with the "Plastic Tensile Test" program (sample base length $-20 \mathrm{~mm}$, width $-20 \mathrm{~mm}$, thickness $-0.1 \mathrm{~mm}$, speed stretching - $1 \mathrm{~mm} / \mathrm{min}$ ).

\section{Results and discussion}

It is possible to judge that a liquid has thixotropic properties based on the fact that the flow (or viscosity) curves recorded at different times of shear deformation will be different. This is due to the fact that the temporal prehistory of samples will not be the same in this case, since the time of shear deformations action on the polymer liquid will also be different in this case. Figure 1 shows the dependences of the stress on the shear rate in the CMC-water system, in which the polymer concentration was $3 \mathrm{~g} / \mathrm{dl}$ that were removed for different residence times of the system at a fixed shear rate. For example, when a rheometer made 30 measurements, the shear rate varied from 0.1 to $100 \mathrm{~s}^{-1}$ for $1200 \mathrm{se}$ conds (curve 1). This means that at each point the system was subjected to deformation for 40 seconds. For 
curve 2 in Fig. 4, the shear rate from 0.1 to $100 \mathrm{~s}^{-1}$ changed over 300 seconds, i.e. at each point, the polymer solution was exposed for 10 seconds, etc. Analysis of the curves allows us to say that with a change in the time of shear deformation action on the samples, the dependence of stress on the shear rate for an aqueous solution of CMC changes, although it retains the classical form characteristic of pseudoplastic liquids (curves 1 and 2). The shorter the time of shear deformation action on the polymer solution (that is, the faster the shear rate changes), the greater the stress value (i.e., the greater the viscosity value). A decrease in the time during which the system was exposed to the shear rate to a certain value ( 4 seconds for $3.0 \mathrm{~g} / \mathrm{dl} \mathrm{CMC}$ solution and less) leads to a change in the form of the flow curve dependence to an anomalous form, due to the appearance in the polymer solution of not only tangents (shear), but also normal (directed along the normal to the surface).

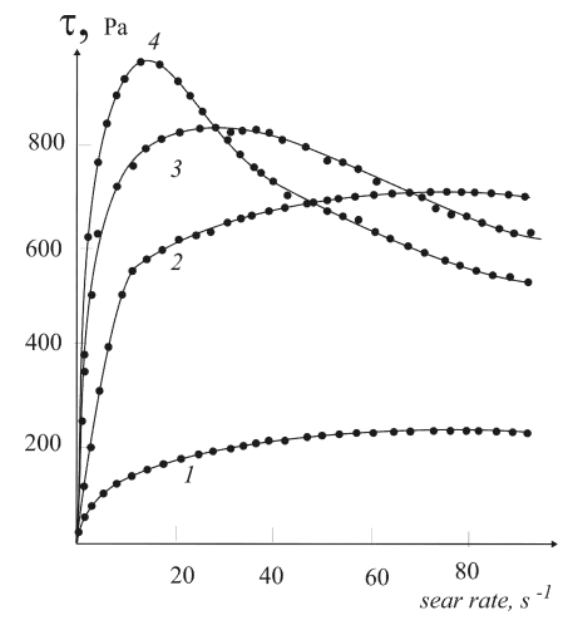

Fig. 1. Dependence of stress on shear rate for a solution with a CMC content in water of $3.0 \mathrm{~g} / \mathrm{dl}$. The time of action of shear deformation on the system was 40 (1), 10 (2), 4 (3), and 2 (4) seconds.

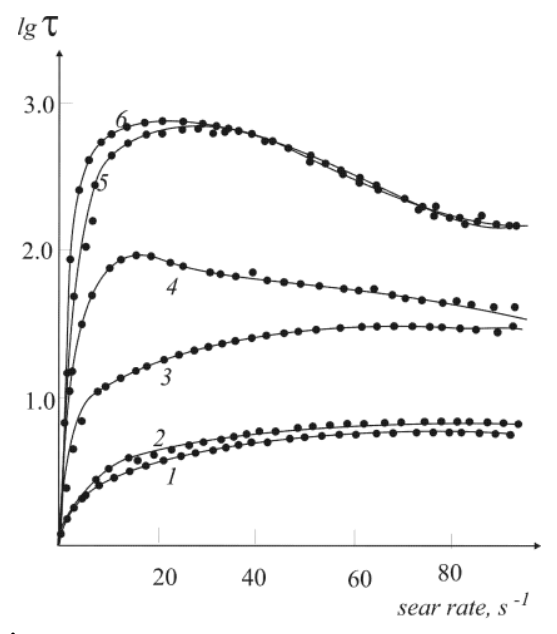

Fig. 2. Dependence of stress on shear rate for CMC solutions in water, with a polymer content of $0.5(1,2), 2(3,4)$ and 5 $(5,6) \mathrm{g} / \mathrm{dl}$. The time of exposure to shear deformation on the system was $40(1,3,5)$ and $10(2,4,6)$ seconds.
Noteworthy is the fact that if the CMC solution is diluted (Fig. 2, curves 1 and 2), then the exposure time does not actually affect the flow curve. This indicates the thixostability of the system. If the solution is halfdiluted, then it exhibits thixotropy (Fig. 2, curves 3 and 4).

In the case of concentrated solutions, strong supramolecular structures are formed. To rebuild them, it takes more time than the experiment. As a result, the concentrated solution is perceived as thixostable (curves 5 and 6 in Fig. 2). Only in the region of semidiluted solutions, the system behaves like a thixotropic one, since the time required for the destruction of supramolecular structures is comparable to the time of the experiment.

It is very important that the rearrangement of the polymer structure in solution, which reflects the presence or absence of thixotropic properties, leads to the fact that the films formed from the solution differ in their physicomechanical characteristics. As it can be seen from Fig. 3, varying the concentration of CMC in the initial solution results in a rather complex change in the physicomechanical characteristics of film materials formed from the solution: in a certain concentration range, with an increase in the polymer content in the initial solution, an increase in the value of the breaking stress takes place. A further increase in the polymer concentration not only leads to a significant decrease in the tensile elongation values, but is also accompanied by a decrease in the tensile stress values. The highest strength is characteristic of films obtained from solutions characterized by the manifestation of thixotropic properties.

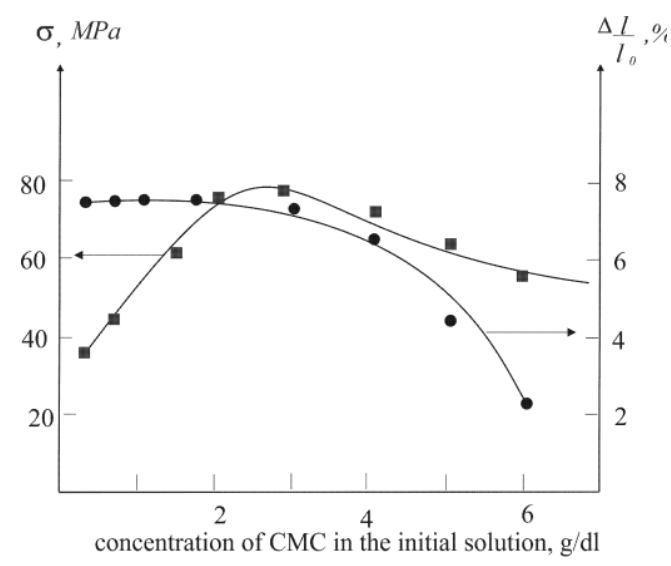

Fig. 3. Dependence of stress and elongation at break for CMC films obtained from initial solutions with different polymer contents.

Thus, the presence of thixotropic structures in the range of intermediate concentrations, where supramolecular structures are unambiguously formed, and the time required for their destruction is comparable with the time of the experiment, makes it possible to regulate some of the physicomechanical properties of materials formed from solutions by varying the level of structure formation of the polymer in the initial solution. 


\section{REFERENCES}

1. Doi M., Edwards S. P. Dynamics of concentrated polymer systems. Part 1. Brownian motion in the equilibrium state // Journal of the Chemical Society, Faraday Transactions 2. 1978. Vol. 74. No. 10. Pp. 1789-1801.

2. De Gennes P. G. Dynamics of Entangled Polymer Solutions // Macromolecules. 1976. Vol. 9. No. 4. Pp. 587-593.

3. De Gennes P. G. Scaling concepts in polymer physics. New York: Cornell University Press, 1979. 324 p.

4. Malkin A., Isaev A. Rheology: conception, methods, applications. Toronto, Canada: ChemTec Publishing, 2005. 465 p.

5. Schramm G. A. Practical Approach to Rheology and Rheometry. Karlsruhe, Federal Republic of Germany: Gebrueder HAAKE GmbH, 1998. 291 p.

6. Chang Dae Han. Rheology in polymer processing. New York, San-Francisco, London: Academic press, 1976. 366 p.

7. Vinogradov G. V., Malkin A. Ya. Rheology of Polymers. Berlin, Heidelberg, New York: Springer-Verlag, 1980. XII. 468 p.

8. Klein J. The onset of entangled behavior in semidilute and concentrated polymer solutions // Macromolecules. 1978. Vol. 11. No. 5. Pp. 852-858.

9. Farnoux B., Nierlich M., Cotton J. P., Boue F., Daoud M., Jannink G. Observation of the collapse of a polymer chain in poor solvent by small angle neutron scattering // J. Chm. Phys. 1978. Vol. 69. No. 4. Pp. 1379-1393.

10. Bradna P., Quadrat O., Dupuis D. Negative thixotropy of solutions of partially hydrolyzed polyacrylamide // Colloid Polym Sci. 1995. Vol. 273. P. 642-647.

11. Szilas A. P. Grid-shell theory, a new concept to explain thixotropy // Rheol. Acta. 1984. Vol. 23. Pp. 70-74.

12. Dullaert K., Mewis J. A model system for thixotropy studies // Rheol. Acta. 2005. Vol. 45. Pp. 23-32.

13. Sadeghy K., Vahabi M. The effect of thixotropy on a rising gas bubble: A numerical study // Korea-Aust. Rheol. J. 2016. Vol. 28. Pp. 207-216.

14. Tager A. A. Physico-khimiya polimerov [Physical Chemistry of Polymers]. Moscow, Nauchnyiy mir Publ., 2007. 576 p.

15. Ilyin S. O., Makarova V. V., Anokhina T. S., Volkov A. V., Antonov S. V. Effect of coagulating agent viscosity on the kinetics of formation, morphology, and transport properties of cellulose nanofiltration membranes // Polymer Science. Series A. 2017. Vol. 59. Iss. 5. Pp. 676-684.

16. Papkov S. P. Physico-khimicheskie osnovy pererabotki polimerov [Physical and chemical bases of polymer solution processing]. Moscow, Khimiya Publ., 1972. 362 p. (in Russian).

17. Ageev E. P., Matushkina N. N., Vikhoreva G. A., Pchelko O. M., Gal'braikh L. S. Dependence of some structural and transport properties of chitosan fi lms on the preparation conditions and the polymer characteristics // Polymer Science. Series A. 2000. Vol. 42. Iss. 2. Pp. 236-241.

18. Udra S. A., Kazarin L. A., Mashchenko V. I., Gerasimov V. I. Kinetic and structural aspects of gelation in polyacrylonitrilepropylene carbonate system // Polymer Science. Series A. 2006. Vol. 48. Iss. 10. Pp. 1105-1109.

19. Torner R. V. Teoreticheskie osnovy pererabotki polimerov [Theoretical Bases of Polymer Processing]. Moscow: Khimiya Publ., 1977. 464 p. (in Russian).

20. Tkacheva N. I., Morozov S. V., Grigor'ev I. A., Mognonov D. M., Kolchanov N. A. Modification of Cellulose as a Promising Direction in the Design of New Materials // Polymer Science. Series B. 2013. Vol. 55. Iss. 7-8. Pp. 409-429.

21. Kuvshinova S. A., Golubev A. E., Burmistrov V. A., Koifman O. I. Modern approaches to chemical modification of cellulose and its derivatives // Ros. Chem. J. 2016. Vol. 60. Iss. 1. Pp. 69-84 (in Russian).

22. Drioli E., Giorno L. Encyclopedia of Membranes. Berlin: Springer, 2016. 2090 p.

23. Edwards J. V., Batiste S. L., Gibbins E. M., Goheen S. C. Synthesis and activity of $\mathrm{NH}_{2}$-terminal and $\mathrm{COOH}$-terminal elastase recognition sequences on cotton // J. of Peptide Research. 1999. Vol. 54. Iss. 6. Pp. 536-543.

24. Rathna G. V. N., Chatterji P. R. Controlled Drug Release from Gelatin-Sodium Carboxymethylcellulose Interpenetrating Polymer Networks // Journal of Macromolecular Science, Part A. 2003. Vol. 40. Iss. 6. Pp. 629-639.

25. Najafi M. P., Ensafi A. M., Reza F. A. Modification of cellulose by graft polymerization for use in drug delivery systems // Colloid and Polym. Sci. 2014. Vol. 292. Iss. 1. Pp. 77-84.

26. Surapolchai W., Schiraldi D. A. The effects of physical and chemical interactions in the formation of cellulose aerogels // Polym. Bull. 2010. Vol. 65. Iss. 9. Pp. 951-960.

Received 25.10.2021. 